\title{
Behavioral Consequences of Optimal Tax Structure - Empirical Analysis"
}

\author{
Stanislav KLAZAR*
}

\section{Introduction}

The methods of classical public finance theory fail in some cases concerning the specific issues of public finance - tax theory and policy. They do not provide reliable and plausible explanations for some social and economic phenomena. Citizens (tax payers) often do not act consistently in their own self-interest. The standard (neoclassical) economic theory assumes that economic subjects (humans, firms) are rational. It means they behave in a way to maximize their individual interest. But (usually) they do not. Consequences of such failures of the theory can lead to unrealistic economic analysis and policy measures (Šeneklová - Špalek, 2009).

Behavioral economy integrates insights from neo-classical economic theory with psychology and there is strong belief it can be a powerful tool to analyze these situations.

Current literature points out moral hazard in case of pension insurance - why is it so difficult to encourage people to save for retirement adequately (Houdek, 2008) and the efficiency of different penalty structures in the tax systems (Pinglu - Yaogen, 2007). The aim of this paper is to review critically the behavioral approach, especially in the field of public finance. The paper will also address the optimal tax system from the point of view of the behavioral economic theory.

\# The article is processed as an output of a research project Public expenditure in postsocialist member states of the European Union registered by the Grant Agency under the registration number 402/09/0283.

Ing. Stanislav Klazar, Ph.D. - assistant professor; Faculty of Finance and Accounting, University of Economics, Prague; <klazar@vse.cz>. 


\section{Behavioral economy and optimal tax system}

Findings and procedures developed by behavioral economy are appropriate complements of classical public sector economic analysis. Definition of optimal tax system used by classics is based on its efficiency and equity. New approach of behavioral economics enriched this field of study. The other necessary thing is the appropriate general opinion of public that it is really effective and fair. To set up such optimal tax system it is necessary to uncover the mechanism how ordinary citizens think about tax (Krishna - Slemrod, 2003 or Kanbur - Pirttila Tuomala, 2006).

Behavioral economic theory offers some recommendation how to show-up the tax system in the more positive manner. It is based on the study of some anomalies occurring in human decision process.

Behavioral economic theory is based on so called "bounded rationality", phenomena firstly introduces by Herbert Simon as a contradiction of classical rationality. Other economists and psychologists expanded this field of study - for a general background on this see Baron (2000) or Kahneman - Tversky (2000).

Behavioral economics basically rests on observation of real human judgment and decision-making. Today we know several types of deviation from ideal (classical) rationality, for example "framing effect" (the same question designed differently can induce different answers, let's say "half full" is preferred than "half empty"). So called "endowment effect" or sometimes "status quo bias" refer to the fact that looses are weighted more heavily than gains.

Other irrationality is described as "isolation effect" (sometimes called "focusing effect"). It occurs when people make decision concerning complex subjects quickly, responding to the most salient and visible aspects ignoring relevant information not immediately perceived by them.

Irrationalities produce inefficiency. The inefficiency is different if produced in private or public sector. Arbitrage mechanism (including stock market and competition for goods) allows profit from the biases to arbitrager so biases are not persistent. In the public sector, in contrast, the biases can persist for long time, because there is not such general arbitrage system, such as a market. McCaffery - Baron (2004) conclude 
that "findings [of behavioral economics] suggest a likely and persistent wedge between observed and optimal public finance."

How can policy makers use behavioral economics findings to established more effectively desirable tax system? Let's focus on the role of "hidden" taxes in the public sector. The "hidden" taxes are characterized by the not usually clear incidence, such as corporate income tax and indirect taxes. They are large and still growing. This kind of taxes is sometimes attractive for policy-makers and for citizens too. There are no serious opponents if some kind of "hidden" tax is imposed. And "it is not obviously in anyone's private interest to lay bare the illusion" (McCaffery - Baron, 2004).

It can be sum up that the favor of "hidden" taxes is based on:

1. the illusion of ordinary tax payer that "I do not pay this tax"

2. the very low benefits for ordinary individuals (voters, not tax advisors!) from fully understanding to the complexity of the tax incidence process and

3. the lack of incentives for lawmaker to reduce the complexity of tax mechanism.

On the other side the tax incidence analysis is hard to evaluate on the citizens basis, but it can be done proximately on the basis of progressivity. And some level of tax progressivity looks like to be a favorable tax system parameter (see Kubátová, 2010; Široký, 2008 or Medved, 2009). People like some degree of tax progressivity, they usually fully understand it is necessary to produce public goods on the basis of solidarity. They prefer "hidden" taxes (see above), but they also generally prefer some level of progressivity. But it is necessarily they are aware of it (see later).

Economic subjects are usually not willing to pay tax. The tax averse (especially for the new ones) induces the government to prefer some kind of hidden tax. There are some ways how to hide the tax. The first one is simply not to use the word "tax" and substitute it by let's say "insurance", "user fees" and so on. Another way is to make the tax indirect, paid in the consumer's prices, or paid by some third party (social security paid by employer or corporate income tax). We can hypothesize that hidden taxes would be "preferred" by economic subjects (and by government too) because people usually do not analyze the effective tax incidence to 
realize, that there is no corporation to bore the tax, but only the citizen. We can call it as some kind of isolation effect, citizens do not consider ultimate effect, only the most salient and visible effects. On the other side we should not reject the indirect (hidden) tax generally. This kind of tax assessment is effective because the direct and indirect tax costs (costs of compliance) are usually lower (see Vítek - Pavel, 2009).

During the next analysis some of behavioral effects will be tested, especially the effect of "hidden" tax (and the effect of uncovering of "hidden" tax), the "preference of progresivity" effect and some kind of "preference of short period incidence" effects. The effects mentioned above predict the citizens will prefer hidden taxes to direct levies because they (citizens) will not feel they are loosing their wealth. During the behavioral experiment some relevant information will be delivered to respondents to improve their thinking about the real tax incidence (and about the tax progressivity too).

There were two parts of empirical analysis examining the two dimension of government action, taxing and spending. We followed the methodology suggested in McCaffery - Baron (2004). The thirst one was concerning the raising money (RAISE) to finance the public goods (tax latency issues), the second one was concerning the direct payments (PAY) for public goods reimbursed through some kind of tax expenditure (progressivity issues).

We compare raising money by an income tax (where the true incidence is visible, known or easily knowable) on the one hand, and by a corporate income tax (this tax is supposed to be fully hidden). Behavioral economic theory suggests the following:

1. Because of tax aversion and greater salience of personal income $\operatorname{tax}(\mathrm{PIT})$

a) At the beginning respondents would tend to oppose an income tax.

b) Later, when citizens realize this tax is relatively higher for rich and smaller for poor, they change their preference to prefer the income tax. 
2. Conversely, respondents will favor corporate income tax (CIT) for its latency until they think about its effect on prices of goods and production factors (labor).

To test implications mentioned above respondents will be prompted about tax impact by relevant information during the survey. It means they should realize the progressivity of PIT (1b) and the real economic impact of CIT (2) somewhere in the middle of survey. Comparison of the preferences before and after this moment can be used to measure the statistical significance of behavioral effects motioned above.

During the second part of analysis (PAY) we compare payment through tax deduction with payment through tax credit. Paying through tax deduction (the tax base is lowered) is regressive (given a progressive income tax structure). It can be hypothesized people would favor deduction until they think about its redistribution effect helping more to the rich then to the poor. Let me derive, that a tax deduction saves more money for those with high incomes than for those with low incomes. The lowest earners pay no tax and thus save nothing from a deduction. Their tax cannot be reduced because there isn't any. But a person who pays (say) $\mathrm{x} \%$ in tax will save $\mathrm{x} \%$ of the cost of anything that is tax deductible.

\section{Survey description}

Respondents were sorted into two groups to enable better analysis of additional information offered during the survey.

Additional information was designed to improve respondent's thinking about progressivity of different way of financing public goods (RAISE and PAY). The order of realizing of new information was different in different groups. One group was forced to analyzed the real incidence and after then the progressivity, the second one was forced to analyze the progressivity effect first and the incidence effect later. The RAISE and PAY questions were identical for both groups.

Survey was divided into six rounds. The RAISE question appeared in part 1, 3 and 5, the PAY question in part 2, 4 and 6 . The baseline conditions and the prompting condition (additional information) were the same for both groups. 
In part 1 of the survey both group of respondents were asked to choose the preferable alternative for RAISE (Q: Dou you prefer the PIT or CIT to raise money for financing the public goods?), to finance the additional public good through increase of personal income tax $($ label +1$)$ or through the increase of corporate income tax (label -1). Additionally, they should evaluate the desirability of such alternative (label 1 for satisfactory, 2 for better and 3 for the best).

In part 2 both group of respondents were asked to choose the preferable alternative for PAY, to finance the additional public good through tax deduction (label -1) or through the tax credit (label +1). Additionally, they should evaluate the desirability of such alternative (see above in part 1). Let me remind that deductions lower the taxable income, and credits lower nominal taxes. So there are different redistribution impacts.

In part 3 respondents were asked to choose the preferable alternative for RAISE (the same question as in part 1), to finance the additional public good through increase of personal income tax or through the increase of corporate income tax. Additionally, the group one (G1) receives information about the different tax incidence of personal income tax and corporate income tax. More precisely: the incidence of corporate income tax on wages and prices of goods and the progressivity on personal income tax were briefly focused and discussed.

In part 4 both group of respondents were asked to choose the preferable alternative for PAY (the same question as in part 2), to finance the additional public good through tax deduction or through the tax credit. Some additional information concerning the redistribution effect of deduction and credit was employed by G2 only (not G1).

In part 5 respondents were asked to choose the preferable alternative for RAISE but new information were delivered to G2 (compare part 3).

In part 6 respondents were asked to choose the preferable alternative for PAY (for the third time) and additional information concerning the redistribution effect of deduction and credits were employed by G1. 
Tab. 1: Survey design

\begin{tabular}{|c|c|c|c|c|c|c|}
\hline \multicolumn{7}{|c|}{ Sequence of survey (part, round) } \\
\cline { 2 - 7 } & $\mathbf{1}$ & $\mathbf{2}$ & $\mathbf{3}$ & $\mathbf{4}$ & $\mathbf{5}$ & $\mathbf{6}$ \\
\hline G1 & RAISE & PAY & $\begin{array}{c}\text { RAISE } \\
+ \\
\text { incidence } \\
\text { of CIT }\end{array}$ & PAY & RAISE & $\begin{array}{c}\text { PAY } \\
+ \\
\text { progressivity } \\
\text { of credits }\end{array}$ \\
\hline G2 & RAISE & PAY & RAISE & $\begin{array}{c}\text { PAY } \\
+ \\
\text { progresivity } \\
\text { of credits }\end{array}$ & $\begin{array}{c}\text { RAISE } \\
+\end{array}$ & $\begin{array}{c}\text { PAY } \\
\text { of CIT }\end{array}$ \\
\hline
\end{tabular}

Note: "RAISE + incidence of CIT" means the additional information concerning the real economic incidence of CIT was delivered to respondents.

Respondents (60 persons) were divided into two groups with 30 subjects. It enabled to study also some crossover effects, so it means interaction of additional information concerning PAY with answers of RAISE question, vice versa. Respondents were the regular students of course Tax theory and policy (Kubátová, 2010).

\section{Results of empirical testing}

The aim of the research was to find out how strong are effects of preference of "hidden" tax and effect of preference of progressivity (and solidarity of public finance). The power of such effects was estimated by the monitoring of changes in answers after the prompting of relevant information to the specific group of respondents.

The response (labeled $(-1)$ for regressive alternative and $(+1)$ for more progressive one) was weighted by the preference of such response (1, 2 or 3 , see above). The results should be closed in the interval from -3 to 3. As mentioned above, the prompted information during the survey should motivate the respondents to move from -3 (regressive, hidden tax) to +3 (progressive alternative).

Let's focus on responses concerning the preference of tax credit and tax deduction (PAY question). At the beginning of the survey it was supposed there would be no difference between alternatives. After the prompting of relevant information the theory predicts the change of 
preference in favor of tax credit. The summary is shown in the following table.

Fig. 1: Weighted response value for PAY questions

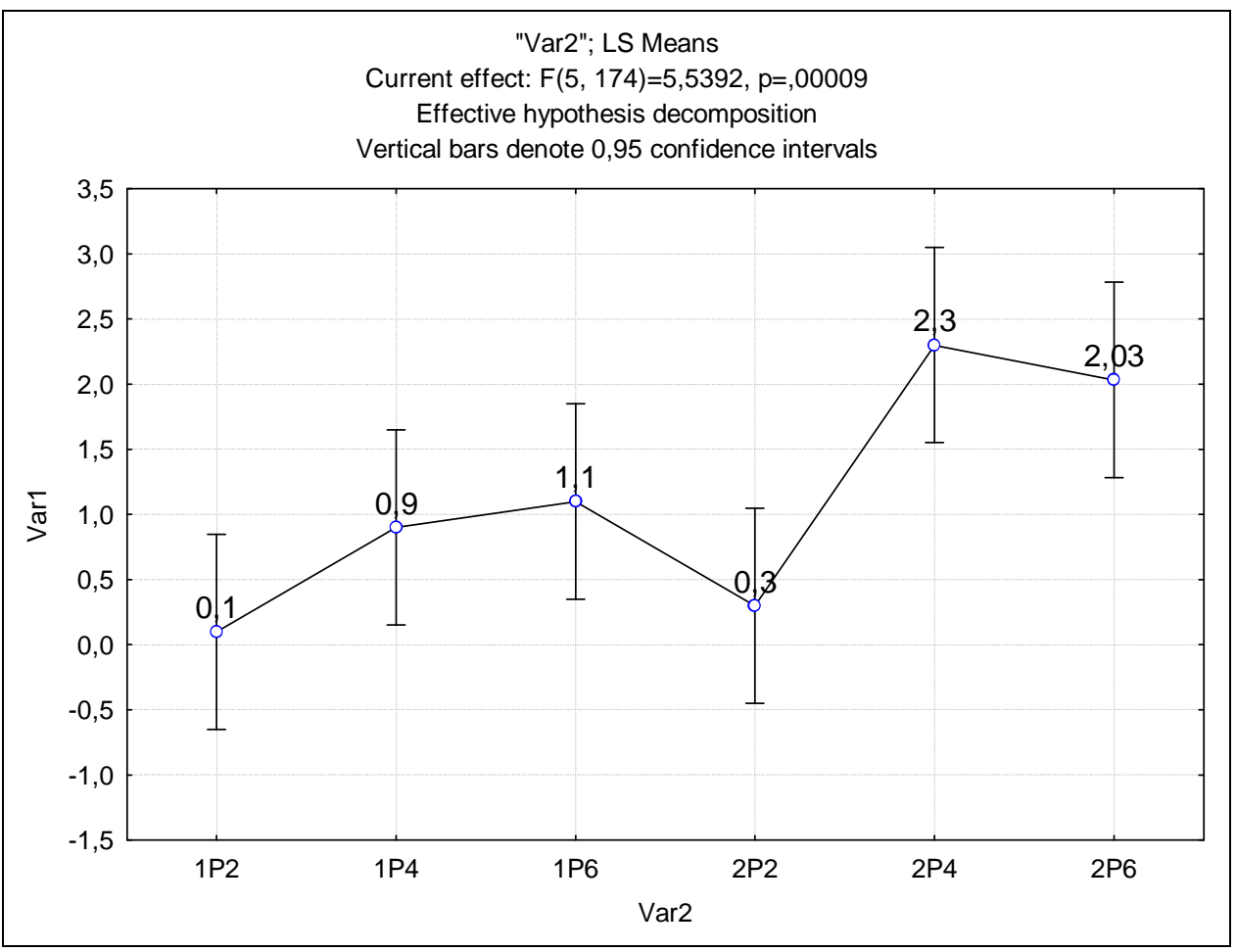

Source: author's calculation.

Where:

1P2 Group 1, PAY question, round 2,

1P4 Group 1, PAY question, round 4,

1P6 Group 1, PAY question, round 6,*

2P2 Group 2, PAY question, round 2,

2P4 Group 2, PAY question, round 4,*

2P6 Group 2, PAY question, round 6

Var1 is average value of responses $(-1$ or +1$)$ weighted by preference (weight from 1 to +3 , integer). The higher value, the more redistributive methods preferred. Compare credit with deduction above.

* indicates prompting (more precisely, this answer could be affected by new relevant information provided to respondent). Notice the order of the prompting is different for G1 and G2.

Let's look at responses of G2 in part $4(2 \mathrm{P} 4)$. There is a significant change from (0.3) to (2.3) and we can hypothesize it is the effect of 
additional information released to this group. Respondents uncovered the regressivity of tax deduction and significantly changed their preferences. This change is statistically significant at 5\% level (see next table).

Tab. 2: T-test results for $2 \mathrm{P4}$ vs. 2P2

\begin{tabular}{|c|c|c|c|c|c|c|c|c|}
\cline { 2 - 8 } \multicolumn{1}{c|}{} & $\begin{array}{c}\text { Mean } \\
\mathbf{2 P 4}\end{array}$ & $\begin{array}{c}\text { Mean } \\
\mathbf{2 P 2}\end{array}$ & $\begin{array}{c}\text { t- } \\
\text { value }\end{array}$ & df & $\begin{array}{c}\text { Std.Dev. } \\
\mathbf{2 P 4}\end{array}$ & $\begin{array}{c}\text { Std.Dev. } \\
\mathbf{2 P 2}\end{array}$ & $\begin{array}{c}\text { F- } \\
\text { ratio }\end{array}$ & $\mathbf{p}$ \\
\hline $\begin{array}{c}\mathbf{2 P 4} \\
\text { vs. } \\
\mathbf{2 P 2}\end{array}$ & 2.30 & 0.30 & 4.06 & 58 & 1.14 & 2.43 & 4.49 & 0.00 \\
\hline
\end{tabular}

Note: Quickly review for results of a t-test for independent samples when the data have been organized by variables. Very low "p" indicates the means are statistical different. Std.Dev. is standard deviation.

After the predicted change of preferences during the part $4(2 \mathrm{P} 4)$ of the survey (notice prompting during this part) there was another change during the part 6 (2P6). This change was with unpredicted magnitude, from (2.3) to (2.03). It means at the end the preferences for progressivity was lower than in the middle of survey, but still remain above the preference from the beginning. This change is not statistically significant at $5 \%$ level, but on $10 \%$ level (see next table).

Tab. 3: T-test results for $2 \mathrm{P} 4$ vs. $2 \mathrm{P} 6$

\begin{tabular}{|c|c|c|c|c|c|c|c|c|}
\cline { 2 - 8 } \multicolumn{1}{c|}{} & $\begin{array}{c}\text { Mean } \\
\text { 2P4 }\end{array}$ & $\begin{array}{c}\text { Mean } \\
\text { 2P6 }\end{array}$ & $\begin{array}{c}\text { t- } \\
\text { value }\end{array}$ & df & $\begin{array}{c}\text { Std.Dev. } \\
\text { 2P4 }\end{array}$ & $\begin{array}{c}\text { Std.Dev. } \\
\text { 2P6 }\end{array}$ & $\begin{array}{c}\text { F- } \\
\text { ratio }\end{array}$ & p \\
\hline $\begin{array}{c}\mathbf{2 P 4} \\
\text { vs. } \\
\text { 2P6 }\end{array}$ & 2.3 & 2.03 & 0.73 & 58 & 1.14 & 1.62 & 2.0 & 0.06 \\
\hline
\end{tabular}

Note: Quickly review for results of a t-test for independent samples when the data have been organized by variables. Very low " $p$ " indicates the means are statistical different. Std.Dev. is standard deviation.

The similar analysis was done for RAISE question. There are summary results. Survey for RAISE was set up to show, how powerful both hidden tax effect and effect of progressivity preferences are. The additional information was designed to uncover the preferences of respondents for personal income tax (progressive tax) in opposition to the corporate income tax ("hidden" tax). The higher value of mean in table, 
the more redistributive methods of financing is chosen and the hidden tax is less preferred.

Tab. 4: Weighted response value for RAISE

\begin{tabular}{|l|c|c|c|}
\cline { 2 - 4 } \multicolumn{1}{c|}{} & 1. part & 3. part & 5. part \\
\hline Mean for G1 & -1.40 & $1.33^{*}$ & 1.33 \\
\hline St. deviation for G1 & 1.62 & 1.81 & 1.81 \\
\hline Meand for G2 & -1.13 & -1.13 & $1.10^{*}$ \\
\hline St. deviation for G2 & 1.80 & 1.80 & 2.12 \\
\hline
\end{tabular}

Note:

G1 a G2 is group one and group two, respectively

* indicates prompting (more precisely, this answer could be affected by new relevant information provided to respondent). Notice the order of the prompting is different for G1 and G2.

St. deviation is standard deviation.

It is evident that the additional information has significant impact on responses and makes the redistributive methods more acceptable. The additional information partly uncovers the latency of corporate income tax and points out the progressivity of personal income tax.

The change of responses for group G1 was from $(-1.4)$ to $(+1.33)$ and for group G2 from $(-1.13)$ to $(1.10)$. It is interesting that the standard deviation is increasing during the survey. It seems the responses became more extreme. Detailed results of statistical significance tests are available by request.

\section{Conclusions}

It is evident that additional information concerning the "hidden" tax and tax progressivity influences the preferences of respondents. The respondents really started to prefer the different ways of financing the public goods, those more progressive.

Effect of "hidden" tax substantially diminishes after the prompting of information concerning the true tax incidence of corporate income tax. At the beginning the corporate income tax was preferred all over the groups, but later it lost its dominance and the alternative personal income tax became the favorable way how to finance of public goods. 
The similar patters can be shown concerning the tax deduction and the tax credit as alternative. The preference of progressivity was uncovered after the additional information was offered to respondents. Some kind of crossover effect is evident from interaction of prompted information for financing by tax (RAISE) and answers concerning the kinds of tax expenditure (PAY). The order of prompted information seems to be relevant factor too.

It is evident the relevant information concerning the real tax incidence and the redistributional effects of particular tax measures can significantly change the citizens view how to construct the preferred tax mix. It might also affect the process of political negotiation and reasoning.

\section{References}

[1] Baron, J. (2000): Thinking and deciding. Cambridge, Cambridge University Press, 2000.

[2] Houdek, P. (2008): Time Preferences in the Perspective of Cognitive Neurosciences. [on-line], E-Logos Electronical Journal for Philosophy, c2008, [cited $13^{\text {th }}$ May, 2010], <http://nb.vse.cz/kfil/elogos/mind/houdek08.pdf>.

[3] Kahneman, D. - Tversky, A. (2000): Choices, values, and frames. Cambridge, Cambridge University Press, 2000.

[4] Kanbur, R. - Pirttila, J. - Tuomala, M. (2006): Non-Welfarist optimal taxation and behavioral public economics. Journal of Economic Surveys, 2006, vol. 20, no. 5, pp. 849-868.

[5] Krishna, A., - Slemrod, J. (2003): Behavioral Public Finance: Tax Design as Price Presentation. International Tax and Public Finance, 2003, vol. 10, no. 2, p. 189-203.

[6] Kubátová, K. (2010): Daňová teorie a politika. Praha, Wolters Kluwer, 2010.

[7] McCaffery, E. J. (2006): Behavioral Economics and Fundamental Tax Reform. Los Angeles, University of Southern California Law and Economics Working Paper Series, no. 3, 2004.

[8] McCaffery, E. J. - Baron, J. (2004): Thinking about Tax. Los Angeles, University of Southern California Law School, Law and Economics Working Paper Series, no. 10. 
Klazar, S.: Behavioral Consequences of Optimal Tax Structure - Empirical Analysis.

[9] Medved, J. et al. (2009): Daňová teória a daňový systém. Bratislava, Sprint, 2009.

[10] Pinglu, C. - Yaogen, C. (2007): Penalty Structure and Individual Tax Evasion: an Approach of Behavioral Public Finance. European Financial and Accounting Journal, 2007, vol. 2, no. 2, p. 25-43.

[11] Šeneklová, J. - Špalek, J. (2009): Jsou ekonomové jiní? Ekonomický model versus realita. Politická ekonomie, Praha, vol. 57, no. 1, pp. 21-45.

[12] Široký, J. (2008): Daňové teorie s praktickou aplikací. Praha, C. H. Beck, 2008.

[13] Vítek, L. - Pavel, J. (2009): Ex post analýza administrativních nákladi̊ energetických daní. In Teoretické a praktické aspekty veřejných financí. Praha, Oeconomica, 2009. 


\title{
Behavioral Consequences of Optimal Tax Structure - Empirical Analysis
}

\author{
Stanislav KLAZAR
}

\begin{abstract}
The aim of the paper was to analyze some behavioral effects, especially the effect of "hidden" tax, the "preference of progressivity" effect and some kind of "preference of short period incidence" effects of citizen. The effects predict the citizens will prefer hidden taxes to direct levies.
\end{abstract}

The behavioral experiments revealed that additional information concerning the "hidden" tax and tax progressivity influences the preferences of respondents. They started to prefer the different ways of financing the public goods, those more progressive.

Effect of "hidden" tax substantially diminishes after the prompting of information concerning the true tax incidence of corporate income tax. At the beginning the corporate income tax was preferred all over the groups, but later it lost its dominance and the alternative personal income tax became the favorable way how to finance of public goods.

It is evident the relevant information concerning the real tax incidence and the redistributional effects of particular tax measures can significantly change the citizens view how to construct the preferred tax mix. It might also affect the process of political negotiation and reasoning.

Key words: Hidden tax; Progressivity of tax; Tax credit; Tax deduction; Behavioral experiments; Experimental economics.

JEL classification: C91, H21, H22, H23 